\title{
Studi Pengaruh Desain Peralatan Postural pada Efisiensi Aktivitas dan Kestabilan Postur Pada Anak dengan Cerebral palsy
}

\author{
Farah Aulia Rahma dan Djoko Kuswanto \\ Departemen Desain Produk Industri, Fakultas Teknik Sipil dan Perencanaan, Institut Teknologi Sepuluh Nopember \\ (ITS) \\ e-mail: crewol@prodes.its.ac.id
}

\begin{abstract}
Abstrak-Anak-anak dengan cerebral palsy (CP) memiliki otot yang lebih kecil, lebih lemah dan lebih tahan terhadap peregangan dibandingkan dengan orang yang biasanya berkembang. CP mengacu pada kondisi permanen, anak-anak dapat belajar untuk mengatasi kondisi saat mereka tumbuh. Terapi dapat memberikan pengobatan seperti terapi untuk duduk pada anak CP. Occupation Treatment merupakan salah satu terapi untuk anak CP yang terdapat pada sekolah luar biasa. Berdasarkan data Kemendikbud, ada 1.962 sekolah khusus di Indonesia dengan 26.617 siswa serta sekitar 1.000 siswa adalah anak-anak dengan CP pada tahun 2016. Namun penggunaan peralatan postural sebagian besar masih menggunakan produk yang digunakan untuk anak normal. Anak-anak dengan $\mathrm{CP}$ memiliki kebutuhan yang berbeda untuk tubuh mereka, seperti adanya kemiringan postur akibat aktivitas yang tidak baik. Tujuan dari penelitian ini adalah untuk mengetahui pengaruh peralatan postural terhadap stabillitas postural dan efisiensi aktivitas belajar pada anak dengan cerebral palsy. Perlengkapan postural yang didesain khusus. Empat peralatan postural digunakan dalam penelitian ini: 1) Seat Postural Equipment, 2) Side Support, 3) sabuk, dan 4) meja pada kursi roda. Pengguna pada penelitian ini merupakan Anak-anak dengan Cerebral Palsy di SDLBD YPAC Surabaya. Hasil penelitian kami menunjukkan bahwa peralatan postural berpengaruh terhadap aktivitas belajar pada anak-anak dengan cerebral palsy dan direkomendasikan rancangan peralatan postural siswa dengan cerebral palsy dalam kegiatan belajar yang diharapkan akan membantu mengoreksi anak dengan postur $\mathrm{CP}$.
\end{abstract}

Kata Kunci-cerebral palsy, postural seat, kursi roda.

\section{PENDAHULUAN}

YEREBRAL PALSY (CP) adalah salah satu penyakit kronis yang ditandai dengan gangguan postur dan gerak nonprogresif [1]. Spastisitas menyebabkan gangguan postur tubuh, gerak kontrol, keseimbangan dan koordinasi sehingga akan mengganggu aktivitas fungsional anak dengan $\mathrm{CP}$ (deformitas).

Perkembangan jumlah anak dengan $\mathrm{CP}$ juga cukup tinggi. Berdasarkan penelitian sesuai rujukan [2] pada tahun 2000, didapatkan data 2-3 bayi per 1000 kelahiran menderita CP. Angka kejadian di Indonesia, anak dengan $\mathrm{CP}$ adalah kurang lebih 5,5 per 1000 dengan rasio penyeimbangan yang sama dalam aspek jenis kelamin, ras, dan negara [3]. Penderita pada usia sekolah dasar. diperkirakan sebesar $1,2-2,5$ anak per 1000 anak. Menurut rujukan [4], prevalensi CP kongenital derajat sedang sampai berat mencapai 1,2 per 1000 anak usia 3 tahun.

CP Diplegia, memiliki angka yang paling besar yaitu $68,8 \%$ menderita diplegia spastik. Diplegia merupakan kelainan yang menyerang kedua tungkai dan kedua tangan, dengan kondisi kaki lebih dominan.

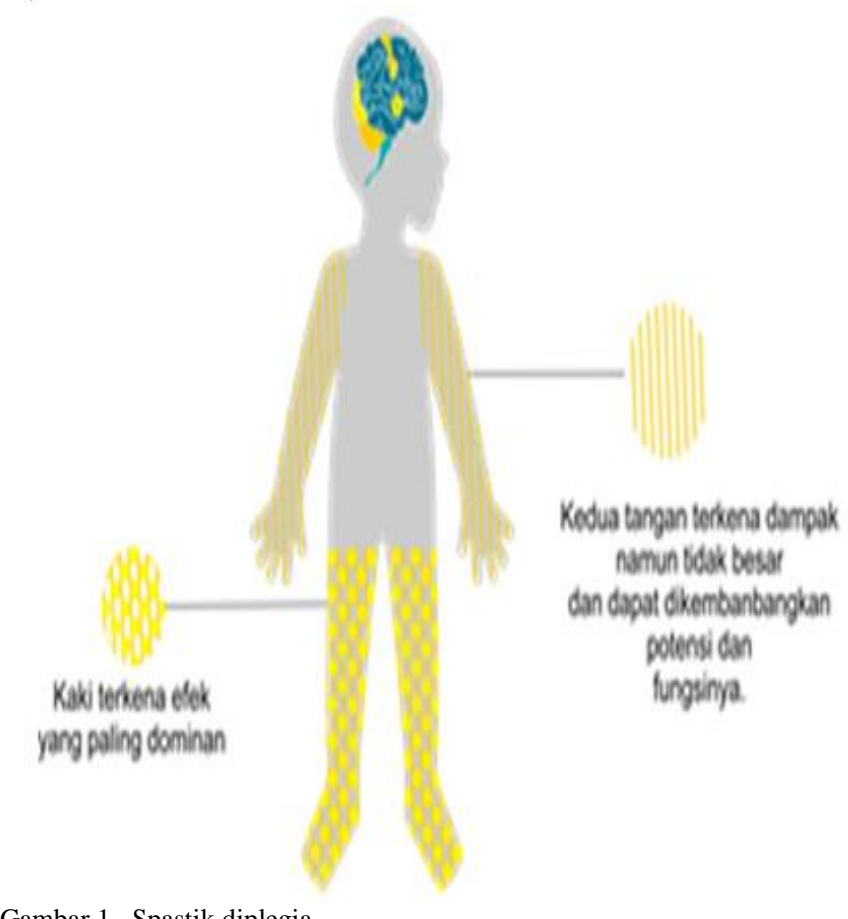

Gambar 1. Spastik diplegia.

Pada otak, terdapat 3 bagian berbeda yang bekerja bersama menjalankan dan mengontrol kerja otot yang berpengaruh pada pergerakan dan postur tubuh [5].

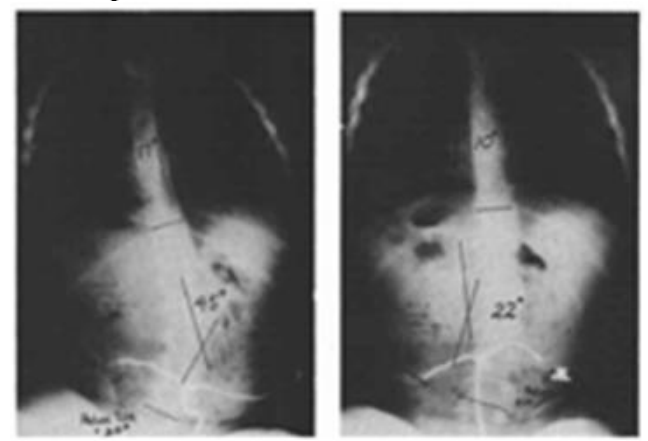

Gambar 2. Postur anak CP pada posisi duduk [6]. 
Anak dengan CP memiliki keterbatasan untuk mengontrol kerja otot yang menyebabkan postur seperti pada gambar 2 diatas. Kondisi tersebut diperburuk dengan kebiasaan aktivitas yang tidak baik seperti pada gambar 3 dibawah. Kondisi inilah yang kemudian dapat memperlamban proses peningkatan kemampuan penderita dan dapat menyebabkan efek jangka panjang seperti bone disease [7].

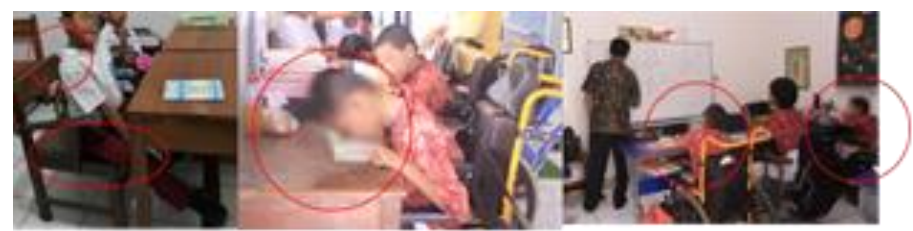

Gambar 3. Posisi Anak pada produk eksisting.

\section{A. Permasalahan}

Berangkat dari latar belakang yang telah dijelaskan di atas dapat diambil kesimpulan bahwa:

1. Sarana pembelajaran kelas SDLB bagian D di Indonesia belum menunjang postur anak CP.

Sarana pembelajaran berupa produk furnitur dan kursi roda yang ada hanya menyesuaikan ukuran ketinggian dan tidak memperhatikan aspek postur sehingga mempengaruhi tumbuh kembang penderita dalam jangka panjang.

2. Sarana pembelajaran yang ada belum bisa menjaga badan anak CP agar tetap tegak.

Anak dengan $\mathrm{CP}$ kurang bisa menyangga badan karena memiliki otot yang lebih kecil, lemah, dan susah diatur dibandingkan dengan anak normal pada umumnya [8].

\section{B. Batasan Masalah}

1. Responden merupakan siswa SDLB dengan CP Diplegia.

2. Penderita yang difasilitasi adalah penderita $\mathrm{CP}$ level II.

3. Desain sarana pembelajaran ini digunakan untuk anak CP dengan rentan usia 7-12 pada 5-50 persentil.

4. Perancangan desain sarana pembelajaran terdiri dari meja dan postural equipment pada kursi dan kursi roda, dilengkapi dengan meja.

\section{METODE PENELITIAN}

Untuk memenuhi kebutuhan pada posisi duduk anak dengan CP dibutuhkan empat titik tekanan atau gaya yang perlu diberikan pada anak dengan $\mathrm{CP}$, yaitu penyokong pada paha, penyokong lumbar, dan penyokong pinggang. Namun pada anak CP dengan fase yang cukup berat membutuhkan fitur tambahan seperti penyangga kepala agar tidak miring, sedangkan pada anak dengan $\mathrm{CP}$ dengan fase yang berat aspek tersebut masih membutuhkan pengawasan pada panggul dan pinggul termasuk tambahan berupa sabuk agar dapat bekerja secara optimal [6]. Bisa kita lihat pada Gambar 5.

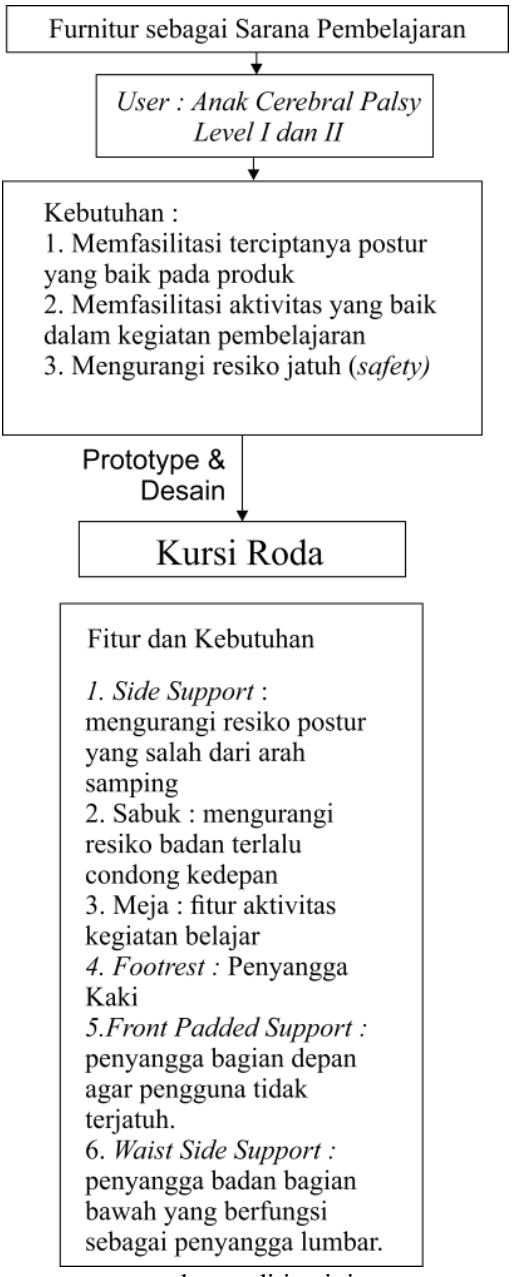

Gambar 4. Alur perancangan pada penelitian ini.
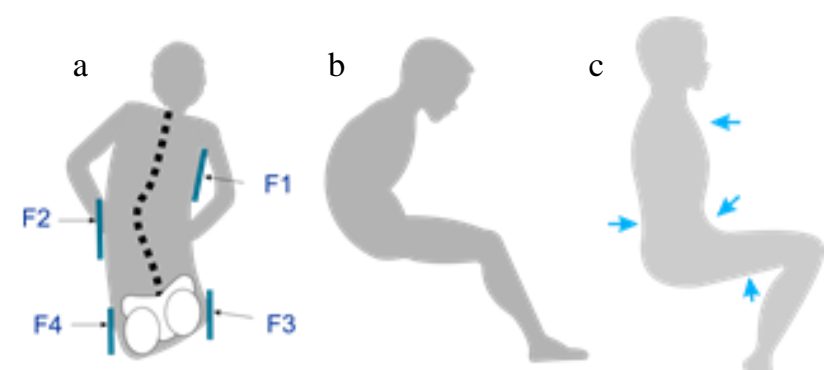

Gambar 5. Sagittal view yang mengilustrasikan pemberian gaya dan tekanan yang dibutuhkan (a), postur miring anak CP berdasarkan tampak samping (b), postur tegak anak CP berdasarkan tampak samping (c).

Aspek biomekanik perlu mempertimbangkan gerak sendi normal pada anak CP. Berdasarkan sudut gerak dalam aktivitas sehari-hari pada anak dengan CP Spastik diperoleh sudut untuk sendi lutut yang flexion pada $60^{\circ}$ dan extension $120^{\circ}$ [8]. 


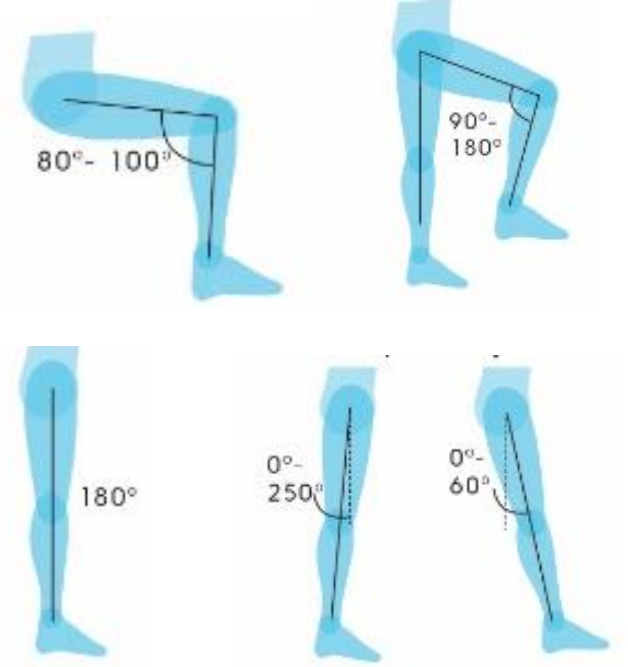

Gambar 6. Sudut Derajat pada pergerakan kai. a) postur duduk, b) menaiki tangga, c) berdiri, d) berjalan [8].

Produk dengan ketinggian menanjak, baik namun tidak boleh terdapat sudut lancip agar memberikan keamanan untuk pengguna. Dibutuhkan bawah dudukan dengan ketinggian $12^{\circ}$ $15^{\circ}$ dengan sudut tumpul yang aman untuk memenuhi kebutuhan anak dengan CP [8]. Berdasarkan data pada Gambar 6 dibawah dapat digunakan pada sudut kemiringan pada kursi yang digunakan sesuai kebutuhan anak $\mathrm{CP}$.

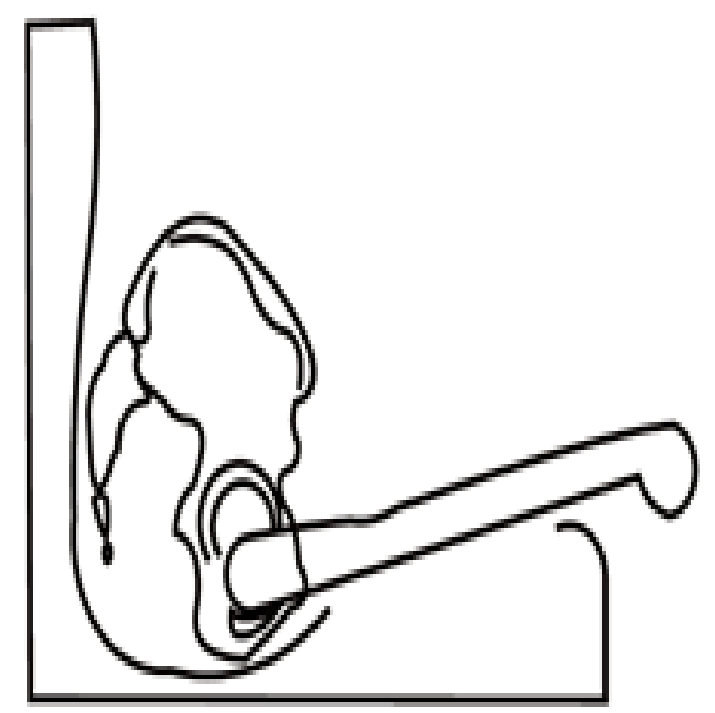

Gambar 7. Posisi kemiringan pada dasar dudukan.

Kemiringan kursi pada $10^{\circ}$ sampai $20^{\circ}$ menunjukkan hasil performasi yang baik. Kursi dengan kemiringan $0^{\circ}$ mengakibatkan penurunan aktivitas otot. Kemiringan yang disarankan merupakan kursi dengan kemiringan $12^{\circ}$ [9], namun aspek tersebut juga perlu mempertimbangkan jangka waktu pemakaian dan aktivitas pada pegguna.

\section{HASIL DAN PEMBAHASAN}

Studi mekanisme folding dua kompetitor memiliki persamaan dengan menekuk pada bagian tengan kursi roda dan adanya kuncian pada bagian atas (Gambar 7).

\section{Gambar 8. Studi Mekanisme Folding Kursi Roda.}

Studi perbandingan fitur berdasarkan Gross Motor Function Classification (GMFCS) atau tingkat kondisi anak CP yang dibandingkan dengan kebutuhannya. Berdasarkan analisis tersebut didapatkan kesimpulan bahwa fitur yang dibutuhkan pada CP diplegia fase II dan III merupakan meja, kursi, dan kursi roda. (Gambar 8).

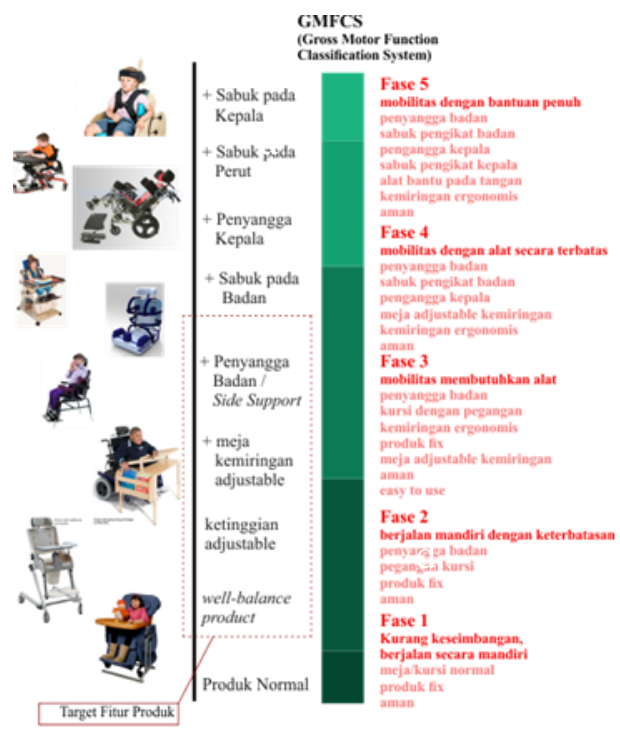

Gambar 9. Studi kebutuhan fitur produk.

Pada sistem reclining dapat kita lihat pada Gambar 9 kompetitor 1 memiliki hanya satu titik tumpu putar pada kursi roda, sehingga memiliki resiko terjatuh yang lebih besar dalam proses reclining dibandingan kompetitor 2 yang memiliki dua titik sumbu pusat.

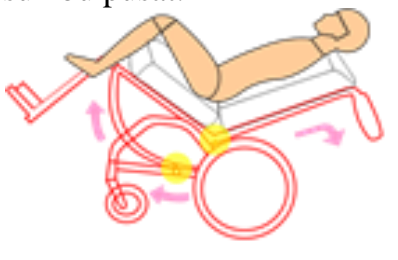

(A)

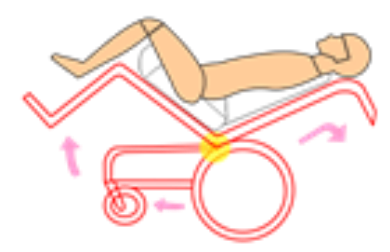

(B)
Gambar 10. Studi Mekanisme Reclining $90^{\circ}$ Kompoetitor 2 (A) Studi Mekanisme Reclining $90^{\circ}$ Kompoetitor 1 (B).

Pada sistem reclining backrest dapat kita lihat pada Gambar 10 kompetitor 1 memiliki hanya satu titik tumpu putar pada kursi roda, sehingga memiliki resiko terjatuh yang lebih besar 
dalam proses reclining dibandingan kompetitor 2 yang memiliki dua titik sumbu pusat.

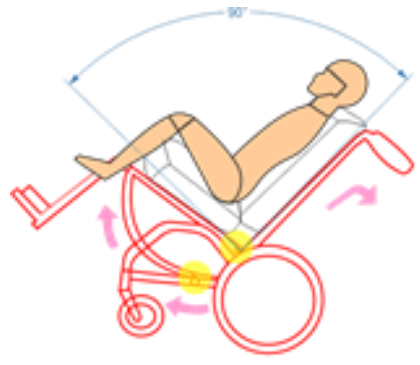

(A)

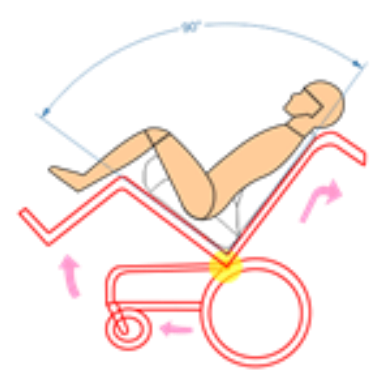

(B)
Gambar 10. Studi Mekanisme Reclining backrest Kompetitor 2 (A) Studi Mekanisme Reclining backrest Kompoetitor 1 (B).

Berdasarkan analisis perbandingan produk tersebut didapatkan beberapa kebutuhan anak $\mathrm{CP}$ dengan komponen yang memberikan solusi atas kebutuhan tersebut. Produk Kompetitor 2 memiliki semua komponen sehingga dapat memberikan kebutuhan bagi anak CP. Produk kompetitor 2 jua memiliki sistem reclining yang terbaik denagn dua sumbu, sehingga produk 2 dipilih sebagai rangka produk.

Side Support System pada alternatif ini menggunakan sistem kuncian dengan sistem operasional sederhana dengan cara menekan handle sistem pengunci kemudian tarik sistem adjustable ke atas dan bawah dan kesamping sesuai dengan ukuran pengguna.

\section{A. Side Support System : Stop and Go}

Side Support System dengan sistem stop and go menggunakan sistem operasional dengan cara tekan dan tarik pengunci sistem push kemudian tarik sistem adjustable ke atas dan bawah dan kesamping sesuai dengan ukuran pengguna yaitu anak $\mathrm{CP}$.

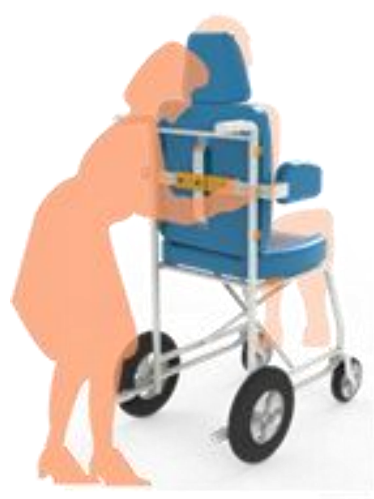

(A)

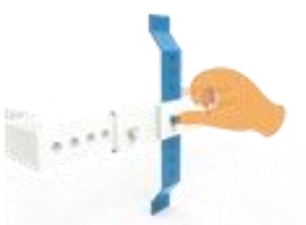

(B)

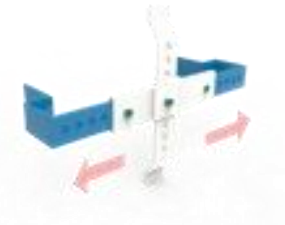

(C)
Gambar 11. Operasional Sistem Side Support (A), Sistem adjustable pada posisi ke atas dan bawah (B), Sistem adjustable penyesuaian lebar untuk pengguna (C).

\section{B. Side Support System : Sistem Ulir}

Operasional dilaksanakan dengan cara putar ulir kemudian tarik sistem adjustable ke atas dan bawah dan kesamping sesuai dengan ukuran pengguna.

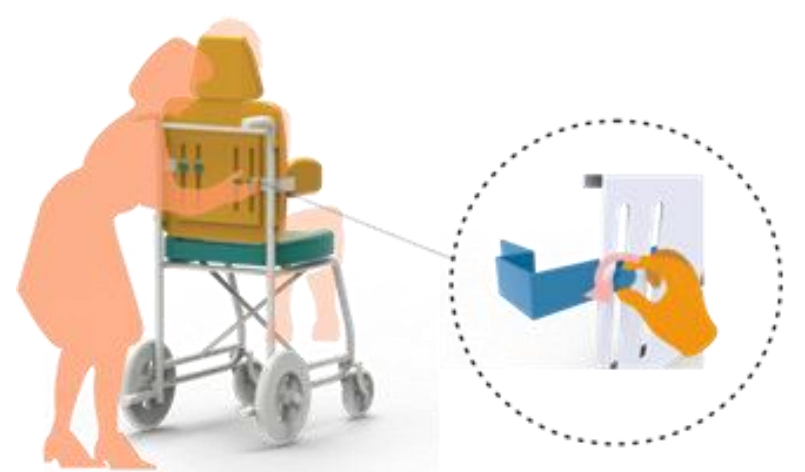

Gambar 12. Operasional sistem side support.

Produk pada penelitian ini terdiri dari seat postural equipment, yang bisa dipakai untuk kursi ataupun kursi roda, meja pada kursi roda, sabuk, dan equipment untuk anak CP. Terdapat sistem adjustable pada side support dan sabuk menyesuaikan dengan ukuran tubuh pengguna.

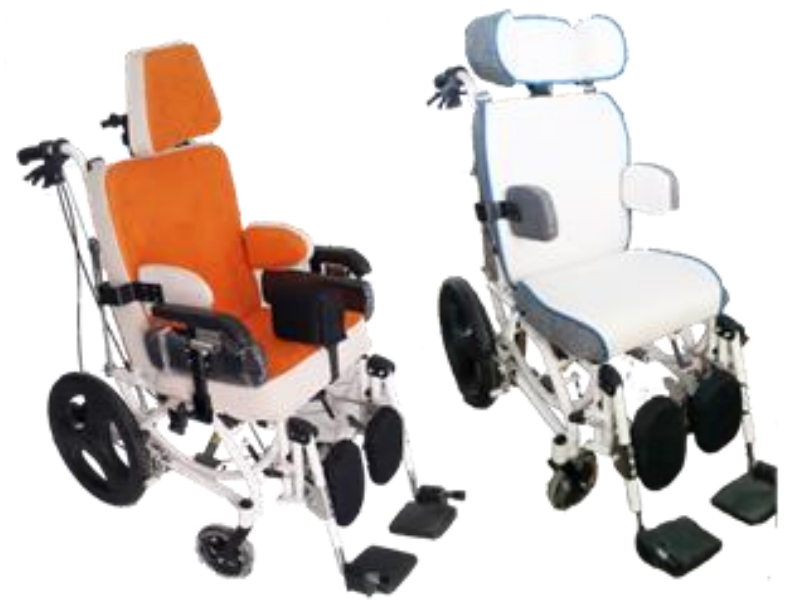

Gambar 13. Hasil desain dari Seat Postural.

\section{Seat Postural Equipment}

Ada dua varian untuk peralatan postural seat ini yang termasuk dengan backreast cushion, seat cushion, dan headrest. Seperti bisa dilihat pada Gambar 13.

\section{Biomechanical Aspect}

Berikut merupakan simulasi daya tekan pada produk dengan pemberian gaya $600 \mathrm{~N}$ pada suport system:

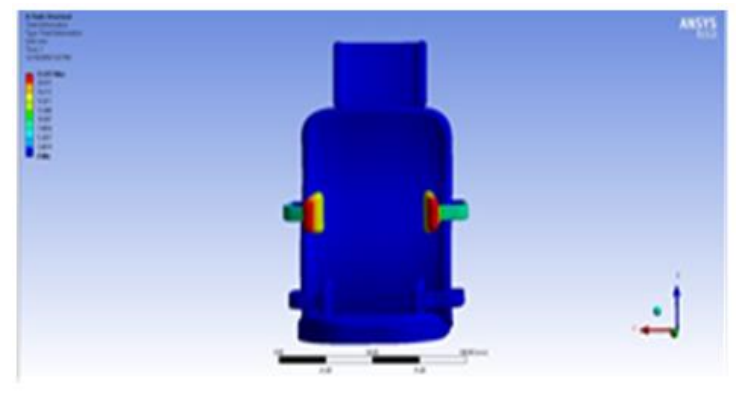

Gambar 14. Ilustrasi simulasi deformation dengan aplikasi ANSYS. 
Tabel 1.

Ilustrasi simulasi deformation dengan aplikasi ANSYS

\begin{tabular}{|c|c|c|}
\hline Alternating Stress MPa & Cycles & Mean Stress MPa \\
\hline 3999 & 10 & 0 \\
\hline 2827 & 20 & 0 \\
\hline 1896 & 50 & 0 \\
\hline 1413 & 100 & 0 \\
\hline 1069 & 200 & 0 \\
\hline 441 & 2000 & 0 \\
\hline 262 & 10000 & 0 \\
\hline 214 & 20000 & 0 \\
\hline 138 & $1 . e+005$ & 0 \\
\hline 114 & $2 . e+005$ & 0 \\
\hline 86.2 & $1 . \mathrm{e}+006$ & 0 \\
\hline \multicolumn{2}{|l}{} \\
\hline
\end{tabular}

Pada Gambar 14 merupakan ilustrasi simulasi deformasi pada support system. Warna merah menandakan titik ekstrem yang mendapatkan akibat dari pemberian gaya.

Tabel 2.

Hasil pemberian gaya $600 \mathrm{~N}$ pada dua titik

\begin{tabular}{|c|c|c|}
\hline \multicolumn{3}{|c|}{ Hasil pemberian gaya $600 \mathrm{~N}$ pada dua titik } \\
\hline Object Name & Fixed Support & \begin{tabular}{|l|l|l|l} 
Force & Force 2 & Force 3 & Force 4 \\
\end{tabular} \\
\hline State & \multicolumn{2}{|c|}{ Fully Defined } \\
\hline \multicolumn{3}{|c|}{ Scope } \\
\hline Scoping Method & \multicolumn{2}{|r|}{ Geometry Selection } \\
\hline Geometry & 2 Faces & 1 Face \\
\hline \multicolumn{3}{|c|}{ Definition } \\
\hline Type & Fixed Support & Force \\
\hline Suppressed & \multicolumn{2}{|r|}{ No } \\
\hline Define By & & Components \\
\hline Coordinate System & & Global Coordinate System \\
\hline X Component & & \begin{tabular}{|l|l|l}
$600 . \mathrm{N}$ (ramped) & $-600 . \mathrm{N}$ (ramped) \\
\end{tabular} \\
\hline Y Component & & $0 . \mathrm{N}$ (ramped) \\
\hline Z Component & & 0. $\mathrm{N}$ (ramped) \\
\hline
\end{tabular}

Tabel 2 menyatakan bahwa pemberian gaya sebesar $600 \mathrm{~N}$ pada 2 titik support yaitu atas dan bawah. Kemudian pada Gambar 15 didapatkan keterangan deformasi yang semakin meningkat sesuai dengan beban yang diterima.

Sehingga disimpulkan bahwa support bagian atas merupakan bagian yang paling kritis dan perlu pemberian desain untuk memberikan kualitas yang baik. Support bagian bawah tidak terlalu mendapatkan efek beban. Sedangkan pada Gambar 16, merupakan analisis kekuatan daya tekan material pada support system.

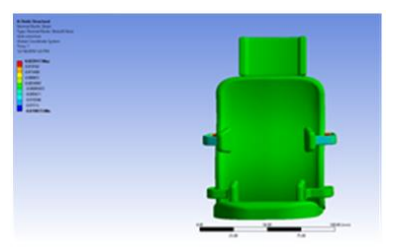

Gambar 16. Simulasi analisis kekuatan daya tekan material pada support system.

\section{KESIMPULAN}

Berikut merupakan kesimpulan dari penelitian. Kesimpulan didapatkan setelah dihasilkan prototype satu berupa kursi roda dan equipment meja serta dilaksanakan usability test kepada siswa di SLDB YPAC Surabaya dan dilakukan wawancara kepada calon konsumen.

1. Setelah dilaksanakan analisis berupa usability test didapatkan hasil bahwa 2 dari 3 siswa didalam satu kelas merupakan pengguna kursi roda, sehingga diputuskan bahwa pembuatan prototype difokuskan pada pembuatan seat postural equipment dengan rangka kursi roda.

2. Desain Postura dapat memenuhi permasalahan yang telah dijabarkan dengan keterangan sebagai berikut:

a. Menunjang Postur Anak CP pada beberapa bagian

b. Memfasilitasi sarana pembelajaran,

c. Rangka kursi roda yang digunakan penulis dipilih untuk memuni kebutuhan pengguna berupa sistem reclining agar mengurangi resiko terjatuh kedepan dengan kriteria pemilihan quipment belajar berupa meja pada kursi roda dengan fungsi magnet agar barang tidak mudah terjatuh.

\section{DAFTAR PUSTAKA}

[1] Potts, Nicki L., and Barbara L. Mandleco. Pediatric nursing: Caring for children and their families. Cengage Learning, 2012.

[2] Chambers, H. G. "Treatment of functional limitations at the knee in ambulatory children with cerebral palsy." European Journal of Neurology 8. s5: 59-74.B. 2001.

[3] Grether, Judith K., Susan K. Cummins, and Karin B. Nelson. "The California cerebral palsy project." Paediatric and perinatal epidemiology 6.3: 339-351. 1992.

[4] Parker, D. F., et al. "Muscle performance and gross motor function of children with spastic cerebral palsy." Developmental Medicine \& Child Neurology 35.1: 17-23. 1993

[5] Bajraszewski, Enver. Cerebral Pals: Guide for Parents. 1989.

[6] Carlson, J. Martin. Seating for Children and Adults with Cerebral Palsy. The American Academy of Orthotists and Prosthetists, 1986.

[7] Janssen-Potten, Yvonne JM, et al. "Chair configuration and balance control in persons with spinal cord injury." Archives of physical medicine and rehabilitation 81.4: 401-408. 2000.

[8] Kuswanto, Djoko, Ni'amah, Syukriyatun and Rahma, Farah Aulia. Development of Orthosis Design for Spastic Cerebral Palsy Through Biomechanical Approach. 2016.

[9] Adnyana. "Cerebral Palsy Ditinjau Dari Aspek Neurologi. Cermin Dunia Kedokteran.”: 34-37. 1995. 